\title{
Science classes: een brug tussen onderwijs en wetenschappelijk onderzoek
}

\author{
A.G.H. van Ruijven
}

\section{Samenvatting}

Om in de huidge Leidse artsopleiding de studenten de mogelikheid te bieden aandacht te besteden aan $h$ wh wetenshappelike vorming, worden facultatef Science classes aangeboden. In vif bijenkomsten van 2,5 ur maken studenten kennis met recente wetenschappelike ontwikkelingen en worden zij getraind in het kritsch beoordelen van wetenschapelike gegevens en in het nadenken over de betekenis van nieuwe wetenschappelike ontwikhelingen voor de medische praktik. De science Classes zin gebaseerd op resultaten van onderzok nadr leren en cognite en op elementen van de methodiek van het problemgesturd leren. De onderwerpen komen voort uit onderoeksprojeten van het Leids Universitai Medisch Centrum en de mentoren zim als onderzoker verbonden aan de projecten. In vele optichten sin de Science Classes en suces. In het nieuwe Leidse curriculum, dat in september 1999 van start is gegaan, is alle keuteonderwijs gebaseerd op de optet van de science classes.

\section{Summary}

In the undergraduate medical curriculum of Leiden Medical School students are offered electwe resecon courses: the science Clases. In five meetings of two and a half hours each the students are introduced to recent scientific developments and they learn how to appraise resecon data and consider the implications of new scientific developments for medical practice. The Science lasses are based on outcomes of research in leaming and cognition and on aspects of problem-based leaming. The subjects are provided by research projects of Leiden University Wedical centre with researchers of these projects acting as course facilitators. The science Clases have been succesf ful in mavy ways. The electve courses of the new Leiden undergraduate curriculum, which started in September 1999, are all modeled on the science classes. (Science Classes: a brige between education and research. Wan Ruiven AGH. Dutch Joumal of Medical Education $2000 ; 19(1) 21-20)$

\section{Inleiding}

De wetenschappelijke vorming van de geneeskundestudent staat in de belangstelling. Deze belangstelling wordt mede gevoed door het Raamplan 1994 Artsopleiding en de aanbevelingen van de visitatiecommissie 1997.1, 2 Vele discussies die door curriculumvormgevers worden gevoerd, hebben betrekking op de vraag wat onder wetenschappelijke vorming dient te worden verstaan en op welke wijze de wetenschappelijke vorming in de opleiding kan worden verwezenlijkt.
In het nieuwe Leidse geneeskundecurriculum, dat in september 1999 van start is gegaan, wordt in de vorm van lijnonderwijs, in vrijwel ieder onderwijsblok en in de co-assistentschappen, aandacht besteed aan de wetenschappelijke vorming van de student. De leerdoelen hebben enerzijds betrekking op het aanleren van vaardigheden die bijdragen aan een kritisch gebruik van resultaten van wetenschappelijk onderzoek en anderzijds op het aanleren van vaardigheden voor het zelfstandig uitvoeren van onderzoek. 
In het huidige curriculum is de wetenschappelijke vorming met name gericht op het doen van onderzoek. Het onderwijs behelst de grondbeginselen van de statistiek en de epidemiologie in het tweede studiejaar en een wetenschappelijk onderzoek van zes maanden in het vierde studiejaar. Om de studenten in het huidige curriculum de mogelijkheid te bieden om kritisch te leren omgaan met resultaten van wetenschappelijk onderzoek, zijn in 1997 door de auteur, onderwijscoördinator inwendige geneeskunde, Science Classes ontwikkeld. In de Science Classes kunnen vierdejaars studenten kennismaken met actuele wetenschappelijke ontwikkelingen. Zij worden getraind in het beoordelen van wetenschappelijke gegevens en in het nadenken over de betekenis hiervan voor de medische praktijk. De opzet van de Science Classes sluit aan bij het wetenschappelijke profiel van het Leids Universitair Medisch Centrum (LUMC). De onderwerpen van de Science Classes komen voort uit onderzoeksprojecten van het LUMC en de mentoren zijn als onderzoeker of expert bij het onderwerp betrokken.

\section{Opzet van de Science Classes}

Een Science Class wordt gevormd door tien studenten en een mentor. Door zelfstudie en vijf bijeenkomsten van 2,5 uur verdiept de student zich in een medisch relevant onderwerp. De tijd tussen de bijeenkomsten is twee á drie weken. De leerdoelen zijn als volgt omschreven:

1. De student kan een uiteenzetting geven van nieuwe ontwikkelingen en discussiepunten in het wetenschappelijk onderzoek met betrekking tot het onderwerp van de Science Class.

2. De student kan een vraagstelling formuleren en gericht literatuurgegevens verzamelen om aan de hand hiervan een antwoord te geven op de vraagstelling en dit antwoord te onderbouwen.
3. De student kan wetenschappelijke gegevens kritisch beoordelen op relevantie en praktische waarde.

4. De student kan in een mondelinge en schriftelijke rapportage de gevolgde werkwijze en de bevindingen en conclusies weergeven en onderbouwen.

5. De student kan de gevolgen van recente ontwikkelingen voor de denk- en handelwijze van de arts aangeven en toepassen op individuele (patiënten)casus.

Ieder jaar worden nieuwe onderwerpen en nieuwe mentoren voor de Science Classes geselecteerd. Bij de keuze van een onderwerp wordt aangesloten bij de actualiteit en nieuwe ontwikkelingen binnen onderzoeksprojecten. De mentoren worden geselecteerd op basis van betrokkenheid bij lopend onderzoek en didactische kwaliteiten. De taak van de mentor bestaat uit het begeleiden en faciliteren van het leerproces, het aanreiken van inhoudelijke informatie en het beoordelen van de studenten. Om de mentor te ondersteunen bij deze, vaak nieuwe rol, is een didactische handleiding geschreven en wordt een instructie verzorgd. De studenten ontvangen eveneens een handleiding en een instructie. Een aantal voorbeelden van onderwerpen die de afgelopen jaren in de Science Classes zijn behandeld, staat in tabel 1.

\section{Onderwijsmethodiek}

De Science Class start met een algemene oriëntatie op het onderwerp, waarbij aandacht wordt besteed aan de relevantie van het onderwerp voor het handelen van de arts en/of de gezondheidszorg. De bijeenkomsten krijgen vorm aan de hand van een door de mentor ingebrachte korte tekst. Dit kan een zelfgeschreven tekst zijn of een tekst uit bijvoorbeeld een krant of een patiëntenfolder. De tekst wordt geanalyseerd en besproken. Aan de hand van de 
Tabel 1. Voorbeelden van Science Classes.

Beenmergtransplantatie
Adipositas
Lichaamssparende ingrepen bij bottumoren
Kanker en immunotherapie
Lichaamsbeleving
Atherosclerose
Prenatale diagnostiek en therapie
De behandeling van levertumoren
Huidkanker en UV straling

vragen die de tekst oproept, worden door de studenten drie vraagstellingen geformuleerd. Per bijeenkomst kiezen drie studenten ieder een vraagstelling en werken deze uit met behulp van een literatuurstudie. Het gebruik van Internet bij het opzoeken en selecteren van informatie wordt gestimuleerd. ${ }^{3}$ De student doet tevens ervaring op met het kritisch lezen van artikelen en het combineren van gegevens uit verschillende artikelen. In de bijeenkomst die volgt, rapporteren de studenten over de uitwerking van de vraagstellingen in de vorm van een presentatie van tien minuten. De student ontvangt feedback op zowel de inhoud van de presentatie als de uitvoering: structuur, tijdmanagement en presentatietechniek. Vervolgens wordt gediscussieerd over de conclusies en de betekenis van de wetenschappelijke bevindingen voor de medische praktijk. De resultaten van de literatuurstudie en de presentatie worden door de student beschreven in een verslag van drie pagina's. Dit wordt beoordeeld op inhoud, structuur, taalgebruik en lay-out.

Bovenstaande herhaalt zich tot iedere student aan de beurt is geweest. Steeds worden aan de hand van een tekst drie nieuwe vraagstellingen geformuleerd, die voor de volgende bijeenkomst worden uitgewerkt. In de laatste bijeenkomst wordt als afsluiting van de Science Class een activiteit georganiseerd die de vraagstellingen en discussies illustreert. Zo is in het kader van de Science Class Ziekte van Huntington een bezoek afgelegd aan een Huntington- afdeling in een verpleeghuis. Tijdens de Science Class Lichaamsbeleving zijn gesprekken gevoerd met asielzoekers over de beleving van ziekte en gezondheid in het land van herkomst en de omgang met artsen in Nederland, en ter afsluiting van de Science Class Mammacarcinoom hebben studenten een biopsie bijgewoond van de schildwachtklier.

\section{Beoordeling}

De Science Classes worden aangeboden als keuzeonderwijs buiten het reguliere curriculum. Aan studenten die met een voldoende resultaat deelnemen aan een Science Class worden twee prestatiebeurspunten toegekend. Tijdens de bijeenkomsten wordt per student een beoordelingsformulier door de mentor bijgehouden. De eindbeoordeling van de student is gebaseerd op: inzet, de presentatie en het schriftelijk verslag.

\section{Onderwijskundige achtergrond}

De opzet van de Science Classes is gebaseerd op resultaten van onderzoek naar leren en cognitie, die ook in probleemgestuurd onderwijs worden toegepast.

Een van de meest consistente bevindingen in dit onderzoek is dat de reeds aanwezige kennis van grote invloed is op de manier waarop, en de mate waarin nieuwe kennis wordt opgenomen. ${ }^{4}$ De teksten die besproken worden in de Science Class, sluiten aan bij het (voor)kennisniveau van de studenten en tijdens de analyse wordt de reeds aanwezige kennis geactiveerd en toegepast. In veel Science Classes wordt voorafgaand aan de eerste bijeenkomst een voorbereidingsopdracht uitgedeeld. Deze opdracht is bedoeld om de aanwezige kennis op te frissen en ook een gemeenschap- 
Figuur 1. Beoordelingsformulier studenten.

Science class

Mentor

Student

Collegekaartnummer

\section{Presentatie}

Inhoud:

Literatuurstudie

Uitwerking vraagstelling

Kritische beoordeling gegevens

Conclusies en argumentatie

Uitvoering:

Structuur van het betoog

Tijdmanagement

Gebruik media

Presentatietechnieken

( gebruik stem, houding, bewegingen, taalgebruik)

onvoldoende/voldoende/goed onvoldoende/voldoende/goed onvoldoende/voldoende/goed onvoldoende/voldoende/goed

onvoldoende/voldoende/goed onvoldoende/voldoende/goed onvoldoende/voldoende/goed

Totaal presentatie:

onvoldoende/voldoende/goed onvoldoende/voldoende/goed

\section{Schriftelijk verslag}

Inhoud:

Beantwoording vraagstelling

Conclusies en argumentatie

Structuur (samenvatting, inleiding, vraagstelling,

(zoek)methode, resultaten, discussie, conclusie)

Lay-out/taalgebruik

Totaal schriftelijk verslag:

onvoldoende/voldoende/goed onvoldoende/voldoende/goed

onvoldoende/voldoende/goed onvoldoende/voldoende/goed onvoldoende/voldoende/goed

Inzet

Betrokkenheid (actieve deelname, geïnteresseerde indruk, bereid zich voor)

onvoldoende/voldoende/goed

Deelname aan discussie (stellen van vragen, geven van mening, onderbouwen van uitspraken, openstaan voor nieuwe informatie en visies, kritische houding, luisteren)

onvoldoende/voldoende/goed

Totaal inzet: onvoldoende/voldoende/goed

Totaal Science class Eindcijfer:

Toelichting: 
pelijk voorkennisniveau te creëren. Uit onderzoek blijkt eveneens dat nieuwe kennis beter wordt onthouden en herinnerd als studenten de kennis hebben uitgewerkt.4, 5 Deze uitwerking krijgt in de Science Classes vorm tijdens de tekstanalyse en de discussies door onder andere het formuleren van vragen, het bedenken van verklaringen en het beredeneren van mogelijke gevolgen van nieuwe ontwikkelingen voor de medische praktijk.

Hedendaagse theorieën over leren en cognitie benadrukken het belang van actief leren, onder meer voor het ontwikkelen van vaardigheden voor zelfstandige, continue scholing na de opleiding. 6 De opzet van de Science Classes is gebaseerd op actieve deelname door de studenten aan het onderwijs. Zij bepalen en verzorgen het grootste deel van het onderwijs zelf.

Veel onderzoeken wijzen erop dat competentie met name wordt verkregen als de student leert bepaalde cognitieve acties te ondernemen. ${ }^{7}$ De leerdoelen die in de Science Class worden nagestreefd, hebben betrekking op het aanleren van cognitieve vaardigheden. Het maakt in wezen niet uit met betrekking tot welk onderwerp of welke nieuwe ontwikkeling deze vaardigheden worden geleerd. De kennisinhoud van de Science Classes is niet gedefinieerd. De kennis die wordt opgedaan in de bijeenkomsten, wordt bepaald door de interesse van de aanwezige studenten, die zich uit in de vraagstellingen, presentaties en discussies. Het kunnen reproduceren van deze kennis wordt niet getoetst.

Ten slotte blijkt uit onderzoek naar studiemotivatie dat intrinsieke interesse voor een onderwerp ertoe leidt dat er meer tijd wordt besteed aan studie. ${ }^{8}$ Dit levert een beter leerresultaat op. ${ }^{9}$ Doordat de studenten zelf de vraagstellingen formuleren en kiezen, wordt de intrinsieke interesse van de student gestimuleerd. In de teksten die de mentor aanbiedt, en in de discus- sies wordt aandacht besteed aan de relevantie van de stof voor de (latere) medische praktijk. Ook basaal wetenschappelijke aspecten worden bij voorkeur gepresenteerd in de context van een klinisch probleem. In de evaluatie geven studenten aan dat ze meer uren studie besteden aan een prestatiebeurspunt voor een Science Class dan aan een studiepunt in het reguliere curriculum.

\section{Evaluatie}

Uit de schriftelijke en mondelinge evaluatie blijkt dat zowel studenten als mentoren zeer positief oordelen over de Science Classes. De studenten ervaren de Science Classes als zeer leerzaam en interessant. $\mathrm{Zij}$ zijn enthousiast over het actief bezig zijn met de stof en de diepgang die in de literatuurstudie en de discussies ontstaat. Het kleinschalige karakter en de interactie met medestudenten en de mentor worden bijzonder gewaardeerd. Studenten geven aan na het volgen van een Science Class kritischer met hun studie en leerboeken om te gaan. Zij worden zich bewust van het feit dat er vaak niet één antwoord of oplossing is en ze leren omgaan met onzekerheid. Ook de houding ten opzichte van wetenschappelijk onderzoek verandert. Studenten vertellen een positievere houding te hebben ontwikkeld ten aanzien van het zelf verrichten van wetenschappelijk onderzoek.

Voor de mentoren is het ook "extracurriculair" onderwijs. Niettemin zijn zij enthousiast over de onderwijsvorm. Het praten met geïnteresseerde studenten over een onderwerp waar zij zelf zo nauw bij betrokken zijn, lijkt op te wegen tegen de tijdsinvestering. De discussies worden als stimulerend ervaren en de frisse en onbevangen reacties van de studenten als inspirerend voor het eigen wetenschappelijk werk. Een bijkomend gevolg van de Science Classes is dat een aantal studen- 
ten hun onderzoekstage of een extra onderzoek bij het onderzoeksproject van de mentor invult. Door de intensiteit van het contact tijdens de Science Class is de mentor goed in staat geschikte studenten te selecteren. De studenten zijn reeds ingewerkt in het onderwerp en kennen de achtergrond van het onderzoeksproject.

\section{Beschouwing}

Bij veel medische faculteiten hebben onderwijs en wetenschappelijk onderzoek een concurrerende positie ten opzichte van elkaar. De Science Classes zijn een poging om deze twee kernactiviteiten van een universitair medisch centrum met elkaar te verbinden en juist van elkaar te laten profiteren. De integratie heeft een positief effect op de kwaliteit van het onderwijs, inspireert de onderzoeker en maakt de studenten enthousiast voor het zelf verrichten van wetenschappelijk onderzoek. In een periode van twee jaar zijn de Science Classes uitgegroeid tot populair onderwijs. De interesse onder de studenten is dermate groot dat bij de inschrijving een lotingssysteem wordt gehanteerd. De mentoren hebben zich vanaf de start enthousiast ingezet en aan hen is veel van het succes te danken. $\mathrm{Na}$ twee jaar Science Classes wordt het als een eer ervaren wanneer je wordt uitgenodigd om een Science Class te verzorgen.

In het nieuwe curriculum vindt een gedegen wetenschappelijke vorming plaats, waarin ook aandacht is voor wetenschapsfilosofie en informatie- en communicatietechnologie (ICT). De Science Classes zijn onderdeel van het keuzeonderwijs in het tweede en derde jaar. De manier waarop de Science Classes zijn opgezet, is ook de basis voor het overige keuzeonderwijs in die studiejaren.

\section{Literatuur}

1. Metz JCM, Pels Rijcken-Van Erp Taalman Kip EH, Brand-Valkenburg BWM van den. Raamplan 1994 artsopleiding; eindtermen van de artsopleiding. Nijmegen: Universitair Publikatiebureau Katholieke Universiteit Nijmegen; 1994.

2. VSNU-Visitatiecommissie Geneeskunde en Gezondheidswetenschappen. Onderwijsvisitatie geneeskunde en gezondheidswetenschappen. Utrecht: Vereniging van Samenwerkende Nederlandse Universiteiten; 1997.

3. Steeg HC van de, Jong PGM de, Bloemendaal PM. De mogelijkheden en meerwaarde van Internet voor medisch onderwijs. In: Verweij AMJJ, Albersnagel EA, Cate ThJ ten, Denekens J, Dikkers JH, Remmen R et al. Gezond Onderwijs-7. Houten/ Diegem: Bohn Stafleu Van Loghum; 1998. p. 2957.

4. Anderson JR. Cognitive psychology and its implications. New York: Freeman; 1990.

5. Schmidt HG, Volder ML de, Grave WS de, Moust JHC, Patel VL. Explanatory models in the processing of science text: the role of prior knowledge activation through small-group discussion. Journal of Educational Psychology 1989;4:610-9.

6. Dolmans DHJM, Snellen-Balendong H, Wolfhagen HAP, Vleuten CPM van der. Seven principles of effective case design for a problem-based curriculum. Med Teach 1997;19:185-9.

7. Glaser R. The maturing of the relationship between science of learning and cognition and educational practice. Learning and Instruction 1991;1:129-44.

8. Cooley WW, Leinhardt G. The instructional dimensions study. Educational Evaluation and Policy Analysis 1980;1:7-25.

9. Schmidt HG. Intrinsieke motivatie en studieprestaties: enkele verkennende onderzoekingen. Pedagogische Studiën 1983;60:385-95.

De auteur

Drs. AG.H. van Rujwen is coordinator Science Classes en onderwiscoordinator bij de Afdeling onderwis Inwendige Geneskunde wan het Leids Universitair Medisch centrum.

\section{Correspondentieadres:}

A.G.F. van Ruiven, Leids Universitair Medisch Centrum, kamer C5 - 057, Postbus 9600, 2300 RC Leiden, e-mail: A G.H.van_Rujvenodivisie2.medfac. Leidemuniv? 